\title{
Body Politics: Positioning the Pregnant Researcher Amongst Asylum Seekers
}

\author{
Ailbhe Kenny
}

\begin{abstract}
Researcher positionality has gained increased attention in recent years, and music education is following suit. Carrying out research that addresses diversity in music education demands a high level of reflexivity and a problematising of one's own position as researcher. This chapter offers critical insights into the complexity of such a positioning and how research practices might reflect, confirm and/or disrupt the existing 'body politic' that our bodies signify. Researcher positionality is here examined in terms of pregnancy within a research project based at an asylum seeker accommodation centre. Applying a Butlerian lens to the examination, the chapter uncovers how the researcher's pregnant body was 'performed' and became the main focus of 'recognition' amongst the people encountered at the centre. These processes of 'performing' and being 'recognised' as a 'pregnant researcher' manifested in various ways such as gaining access, credibility, trust, relationships, ethical considerations and power. Thus, the chapter opens a space to reflect critically on researcher positionality and specifically its influence on the research process in sites that seek to understand diversity in music education.
\end{abstract}

Keywords Positionality · Pregnant researcher - Identity · Embodied research · Researcher body $\cdot$ Reflexivity $\cdot$ Motherhood $\cdot$ Asylum seeking

\section{Introduction}

Bodies are political. The term 'body politic' has medieval origins where states, towns, guilds, churches and families were considered in such terms - as 'bodies'. As such, the political and social body was understood in a manner similar to the physical, either healthy or corrupt, in need of intervention, often through purging and disciplining. 'Purifications', for example, were as much physical as intellectual

\footnotetext{
A. Kenny $(\bowtie)$

Mary Immaculate College, University of Limerick, Limerick, Ireland

e-mail: ailbhe.kenny@mic.ul.ie 
(consider the expulsion of Jews, witch-hunts, and enclosures of nuns). In contemporary contexts, a 'body politic' can be a nation regarded as a corporate entity, the state or collective unit of people. Such a 'body politic' is known all too well to those who are subjected to racial persecution, sexual harassment and abuse, gender-based violence, reproductive restrictions and disability discrimination, to name but a few. When working with marginalised groups, what becomes especially pertinent in any examination is how our research practices might reflect, confirm and/or disrupt the existing 'body politic' - essentially the power structures and political histories - that our bodies signify.

Researcher positionality has gained increased attention across scholarly domains in recent years, and music education is following suit. The complexities of positionality are manifold, often attributed to race (Milner 2007), gender (Butler 1999) and class (Hurst 2008), not to mention other polarities such as insider/outsider, practitioner/researcher, performer/writer and teacher/learner. Carrying out research that addresses diversity in music education demands a high level of reflexivity and a problematising of one's own position as researcher. This chapter highlights the role of the music education researcher as 'embodied' and 'situated'. As Cousin (2010) reminds us, "The self is not some kind of virus that contaminates the research. On the contrary, the self is the research tool, and thus intimately connected to the methods we deploy" (p. 10). The chapter opens a space to reflect critically on researcher positionality and specifically its influence on the research process in sites that seek to understand diversity in music education and 'the marginalised'.

Taking one site-specific case study in Ireland, I interrogate my own researcher position within a participatory research project that sought to examine the musical lives of children of asylum seekers. The research involved music workshops, focus group interviews, video data and researcher reflective logs over a 3-month period at a temporary communal accommodation centre for asylum seekers. Drawing on my 'field identity' (Srivastava 2006), within a space that is separated from society at large, there are multiple facets to consider in the discussion of positionality. I am white, Irish and female. I was also both music facilitator and researcher within the project. Negotiating, enacting and performing these numerous positions could not be separated from the research itself, and thus these 'multiplicities of identities' (Ruppel et al. 2008) influenced and shaped the research process. Of particular focus for this chapter is that I was also pregnant while carrying out the research fieldwork. Applying a Butlerian lens to the examination, I will highlight how my pregnant body was 'performed' (1999) and became the main focus of 'recognition' (2004) amongst the people I encountered within the research. These processes of 'performing' and being 'recognised' as a 'pregnant researcher' manifested in various ways such as gaining access, credibility, trust, relationships, ethical considerations and power. Thus, the chapter offers critical insights into the complexity of such a positioning for researchers in the field. 


\section{2 (Em)Bodied Research}

The concept of 'researcher as instrument' is well established across qualitative research and literature. This concept highlights the distinctive function and influence of the researcher's background, knowledge, perspective and subjectivity that they bring to the research, arguably influencing the process from conceptualisation through to fieldwork, analysis, interpretation and finally write-up. Ellingson (2006) states, "Rather than apologizing for our subjectivity or simply stating our 'biases,' we should instead carefully consider how ourselves and our experiences influence our research processes" (p. 307). Using the concept of 'researcher as instrument' as a point of departure, viewing research as an 'embodied practice' (Coffey, 1999) pushes us further to consider the researcher's body itself - how it looks, is perceived, is positioned, is classified, etc. - and how such a body matters to the research process and research accounts given.

Embodied research takes a reflexive position, seeing researcher as both agent and participant in the research process. Bresler (2008) claims that researchers, "research who we are" (p. 267). The performativity of the research encounter and the role played by all participants are also in focus here. As such, how the researcher and research participants inscribe material and discursive dimensions on the body during the research journey (from access through to writing) is problematised. These identities are inevitably intersectional and context-dependent and according to Bresler involve a "mutual shaping" between "the experience of being a researcher and on how this experience shapes who we are" (2008, p. 268).

Research carried out with asylum seekers, and children of asylum seekers, immediately distinguishes them as 'other', just as is often the case with research exploring any marginalised communities. Acknowledging, and more importantly interrogating, the relationship between power and identity is therefore called for. Ellingson (2006) notes:

It is the privilege of the powerful to leave their bodies unmarked. . .today it is the privilege of being unmarked, of having one's positionality obscured as the norm that signifies power. White bodies, for example, are rarely noted by authors, whereas bodies of people of color are marked in texts as "different"... (p. 301)

When researcher bodies are 'neutralised', or 'written out', Ellingson goes on to argue, "they reinscribe the power of scholars to speak without reflexive consideration of their positionality, whereas others' voices remain silent or marginalised by their marked status" (2006, p. 301). Simply stating researcher biases therefore is not enough. An examination of how research participants relate to the researcher, their own perceptions and assumptions, their willingness to participate in the research, how access is obtained, how the environment shapes the research, why some actions are constrained while others are enabled, etc. all require problematising. In short, an embodied approach to research needs to not just explore how the researcher views themselves but also how the researcher is viewed by others. 


\section{Situating the Body}

The continuing worldwide migration 'crisis' has brought about many challenges including the controversial nature of asylum seeker accommodation. Direct Provision (DP) was set up in Ireland in the year 2000 as a state system of housing asylum seekers with an average time period spent inside these centres of 4 years. The system accounts for almost 6000 residents, of which one third are children. There are $47 \mathrm{DP}$ centres across Ireland where the types of accommodation provided include hostels, guesthouses and holiday camps. These shared, communal, temporary accommodation settings for asylum seekers create 'accidental communities' (Malkki 1997; Weston and Lenette 2016); the people within them have not come together out of choice but rather from a 'zone of exclusion' (Malkki 1997). My research to date has focussed on how asylum seekers and children of asylum seekers participate musically and potentially form 'communities of musical practice' (Kenny 2016) within these accommodation centres.

For the purposes of this chapter, I revisit a study carried out in one DP centre in the mid-west of Ireland (see Kenny 2018). The research took a qualitative case study approach where I was both researcher and music facilitator. Music workshops were carried out with a group of 7-12 year olds between April and June 2016 involving activities such as group song-singing, ensemble playing with small handheld instruments, group composition, vocal improvisation, performance and listening tasks. As part of a varied methodological approach, a researcher reflective log was kept recording thoughts and observations directly following each workshop. Upon reflecting on my researcher positionality for this chapter, I have revisited my field notes and reflective log from this study to focus specifically on how being a pregnant researcher impacted the research process itself, to reflect on my thoughts during fieldwork in relation to this, to examine interactions with my pregnant body, to look at how my pregnancy was defined by others and to trace how being pregnant was negotiated into research practices engaged in.

\section{Performing the Body}

Judith Butler's theory of 'performativity' is a useful lens to bring to this work, particularly in its attempts to critically reflect on researcher positionality as well as offer alternative narratives about research with marginalised communities. In applying this lens, the discussion seeks to examine a common, lived, embodied experience of identity as opposed to highlighting 'difference' between the researcher and the researched community. For Butler (1999), the body is produced through discourse:

Performativity is thus not a singular "act" for it is always a reiteration of a norm or set of norms, and to the extent that it acquires an act-like status in the present, it conceals or dissimulates the conventions of which it is a repetition. (p. 241) 
As such, reality is constructed discursively and performed, not just through language, body norms and physical acts themselves but is also contingent on power relations, historical events and environments. According to Butler then, the subject is made and remade through repetition of these discourses which often support or uphold existing power structures. For example, queer bodies are defined to uphold heteronormativity and bodies of colour, white privilege.

Directly linked to pregnancy are the dominant discourses on motherhood of course - women viewed as virtuous, sacrificial, non-threatening, and all-loving. Both Rose (2018) and Rich (1995) have repeatedly criticised this 'idealisation of mothers' and 'maternal virtue'. Rich (1995, p. xxiv) states, "I do not see the mother with her child as either more morally credible or more morally capable than any other women". Yet, such idealisation is not equal for all women. Motherhood too gets caught up in the political and media frenzies of the day with migration in particular being a target. Rose (2018) writes of the demonisation of "alien mothers" as the "objects of visceral revulsion" in society (p. 167), while Reynolds and Erel (2016) identify how migrant mothers are often projected as 'benefit cheats' and 'welfare scroungers'. This is not just borne out in tabloid headlines but within legislation, where, for example, children born in a host country do not enjoy the same rights as other children or deportations continue to separate parents from children.

Directly related to the focus of this chapter, the heterosexual, female, pregnant, white researcher body represents multiple performativities, holding the complexity of the power that comes from racial and sexual orientation alongside patriarchal and gendered norms, while nestled within dominant discourses of motherhood. In order to be 'a subject' in this research, however, one must be rendered 'recognisable' through regulatory, social and normative discourses (or performativity). Butler (2004) is keen to remind us that such recognition functions as a site of power: "... if the schemes that are available to us are those that 'undo' the person by conferring recognition, or 'undo' the person by withholding recognition, then recognition becomes a site of power by which the human is differently produced" (p. 2). Applying a Butlerian lens then, both I and the other mothers' feasibility as subjects required that we be recognised as such - as mothers - but this was only possible within existing norms and overarching motherhood discourses. Discourses are multiple and shifting of course, and so it is worth pointing out that within interactions with myself as researcher, motherhood offered an alternative identity for the women in the centre that went beyond 'an asylum seeker'. While power imbalances abounded, this shared gendered performativity did offer a level of agency for the women to resist the dominating forces they were subjected to within the accommodation centre (illegal status, enforced poverty, restricted rights and limited food choices to name but a few), even within short periods of interaction. 


\title{
5 The Pregnant Body
}

The pregnant body is a public body. I was 6 months pregnant when I entered the field for this research project, and so I was from the onset, 'a pregnant researcher'. As it was my first pregnancy, I was naïve to both the privileges and constraints such a new body brought with it. The influence of my pregnancy on the research actually began months before embarking on the fieldwork. I was told by a male senior administrator at my institution that I, 'would not be able' to carry out the project and may have to return the funding awarded. Another male colleague on 'congratulating' me, commented, 'that will put a halt to your gallop'. Such comments were not restricted to gender. I also received frequent statements from female colleagues that my publication list would now have a 'massive gap' and that I would have 'different priorities now'. It was clear from the outset, therefore, that being a pregnant researcher (and thus a soon-to-be mother) was awash with political, gendered and moral judgments, freely given without invitation. As Butler $(2004$, p. 21) states, "my body is and is not mine". I was no longer 'recognised' as a female academic but a pregnant female academic.

This new positioning also had its advantages. As far back as 1988, female anthropologists noted how their marriages, pregnancies and motherhood offered access to 'women-centred worlds' (Warren 1988). How my pregnancy influenced access within the research site was most interesting. An extract from my researcher log below 'sets the scene' regarding my first visit to begin music workshops with children at the DP centre:

\begin{abstract}
It is 3.30 pm, time for the music workshop but nobody seems to be waiting or ready. I knock on a door marked 'managers office' and a young woman emerges. She explains that they will need to be 'rounded up', puts on her jacket and goes outside. A lady passes me with a baby in her arms and keeps walking. I am shown the room for the workshop. It resembles a primary school classroom to a large degree and so is very familiar to me. It has posters on the walls, everything is labelled with flashcards, there are whiteboards, there is a teacher's desk, children's desks and chairs. It is bright and colourful but I am surprised at just how much it replicates a classroom. I set about pushing back tables and arranging chairs in a circle to try to create an atmosphere that has not been the same as their school day. I place the musical instrument box of handheld percussion in the middle and wait. And wait. After 20 mins nobody arrives and I decide to go see what is happening. I return to the reception area. (Reflective Log 1).
\end{abstract}

As revealed above, the arranged workshop failed to recruit any children to the designated room. After much angst, I sat down at a couch in the main reception area, hoping that perhaps some children might appear. This is not what transpired however. Instead, my bodily positioning on the couch, while visibly pregnant, enabled other mothers to connect with me, as illuminated in the following log extract:

I sit on the couch and am filled with anxiety. What now? As I contemplate my options, time moves on and I absent-mindedly rub my pregnant belly (perhaps for comfort, perhaps to remind myself that there is life beyond this research project or perhaps both!). The lady who previously passed me carrying a baby has circled round again and on seeing my 'bump' sits 
next to me. She asks the many questions I have become accustomed to since my body announced I was pregnant, 'When are you due?', Is it a boy or girl? How are you feeling? Is it your first?... and I similarly respond by asking the customary questions expected to ask of one carrying a baby, 'What is its name?', 'How old is she?', 'Does she sleep?'... during this exchange another pregnant lady walks by and joins in the conversation, following this two mothers with small toddlers also gravitate toward our expanding group on the couches. After a time, I begin to tell them what I am doing here and ask if they have or know children aged between 7 and 12 (Reflective Log 1).

Following this exchange, the group of children for the workshops are established through these mothers and continue to engage for the project duration. Despite this positive outcome, I was also troubled by the interaction. My pregnancy and imminent motherhood stood in stark contrast to theirs. The relationship between gender, pregnancy and migration politics is never far from public view. According to the United Nations Population Fund (UNFPA), one in five women of childbearing age in crisis settings is likely to be pregnant, and $60 \%$ of all maternal deaths occur in these settings (see https://www.unfpa.org). ${ }^{1}$ Furthermore, asylum seekers and refugees are particularly vulnerable due to arduous journeys often undertaken, their high risk of trauma and exposure to sexual violence, limited access to health facilities and care, enforced poverty, as well as such things as language, culture and social barriers on arrival in the host country.

In my situation, I felt the differences were further exacerbated by the women's obvious illegal status (as well as the illegal status of their children and unborn children) while living at the centre. Yet, my pregnancy facilitated a building of trust and therefore access. It represented in a very explicit way, a common, situated, gendered, embodied knowledge we could all share. And as noted by Rich and Rose earlier, pregnant women are not generally perceived as threatening (rightly or wrongly).

The discourses previously discussed extended to my interactions amongst the children. The girls involved in the music workshops appeared very familiar with pregnancy and were keenly interested in the baby's arrival throughout the project. The log notes here highlight the curious and caring attitude taken towards my physical state:

The girls stay behind as I move back the desks, they rush in to help and ask me questions about my pregnancy, 'is it a boy or girl', 'what will you call the baby', 'when is it coming'? They continue to help me with the chairs and desks as we talk and then walk me all the way out to my car helping to carry the instruments. They wave energetically and yell 'goodbye' as I drive off. (Reflective $\log 3$ ).

The girls were therefore part of the 'women-centred worlds' (Warren 1988) referenced earlier, playing into (and 'performing') gendered norms, cultures and expectations. Not once did a boy in the group query my expanding body week to week. When the girls would ask questions, and sometimes request to rub my belly, the boys would typically look away or busy themselves with an instrument.

\footnotetext{
${ }^{1}$ In contrast, Ireland has one of the world's lowest rates of maternal death, consistently ranking around joint sixth in the world.
} 
Applying a Butlerian framework to this, 'recognition' of my pregnancy was thus also performed by the boys through gendered, cultural, social and perhaps religious norms, just as much as the girls performed them (though in opposite ways). The boys, akin to my male colleagues referred to earlier, were thus through a process of 'repetition' (Butler 1999) performing certain expected norms through such distancing.

\section{Body Matters: Concluding Thoughts}

A researcher's positionality can both be established and shift according to the social, cultural, economic and political values and norms in a given context. This chapter has revealed that even further to this, the researcher's body itself can shape and be shaped by the research process and interactions within it. In particular, it has been shown that 'the pregnant researcher' significantly influenced the research process carried out in an asylum seeker centre in terms of negotiating access to participants, building trust and credibility, establishing (gendered) relationships and influencing interactions. Furthermore, how the researcher was viewed by others, through 'recognition' (Butler, 2004), also defined this role. Through a reflexive examination of this research journey, the importance of considering and revisiting one's researcher identity and positionality is highlighted.

The chapter has also shed light on the complex interplay of migration, politics, identity, the body and gender, as well as the various power dimensions associated with this. I carried with me a certain amount of social, cultural and economic capital into a research context that was inhabited by people seeking asylum. I was also coming from a place of racial privilege within a host country where the research participants sought to gain legal status. The imbalance of power in such a situation is obvious and, yet, commonality was found through the pregnant body and through a dominant virtuous discourse of motherhood (Rich 1995; Rose 2018). While this translated as an acceptance by the females at the centre, it also meant a distancing from the males. This raises questions around how a researcher's body in the field can both be simultaneously inclusive and exclusive.

What is abundantly clear throughout this examination is that any real or perceived boundaries between the 'researcher' and the 'researched' are false. Furthermore, through our discourses and interactions 'in the field', we are 'performing' (Butler 1999) and made 'recognisable' (Butler 2004) within established societal, cultural, historical and political norms. 'Recognition' did indeed act as a site of power in this study but not just for me as researcher but for the migrant mothers encountered. We shared a common lived experience of motherhood/pregnancy that was relational, performative and embodied, therefore connecting the researcher with the researched and countering exclusionary research processes and practices. Furthermore, by acknowledging the body of the researcher in this discussion, it reaffirms a shared humanity with the marginalised female community encountered. It is recommended therefore that researchers pay careful attention to their bodies and their multiple 
positionings when conducting research and writing about it. Researcher reflexivity (including researchers' bodies as integral to this) can thus open up a critical space to destabilise simple truths, challenge power structures and interrogate the taken for granted. Such an embodied approach to research that deals with diversity issues in particular offers exciting opportunities for more nuanced, critical and detailed understandings for the field of music education and beyond.

\section{References}

Bresler, L. (2008). Research as experience and the experience of research: Mutual shaping in the arts and in qualitative inquiry. LEARNing Landscapes, 2(1), 267-281.

Butler, J. (1999). Bodies that matter. In J. Price \& M. Shildrick (Eds.), Feminist theory and the body: A reader (pp. 235-245). New York: Routledge.

Butler, J. (2004). Undoing gender. New YorklLondon: Routledge.

Coffey, A. (1999). The ethnographic self: Fieldwork and the representation of identity. London: Sage.

Cousin, G. (2010). Positioning positionality: The reflexive turn. In M. Savin-Baden \& C. Howell (Eds.), New approaches to qualitative research: Wisdom and uncertainty (pp. 9-18). Abingdon: Routledge.

Ellingson, L. L. (2006). Embodied knowledge: Writing researchers' bodies into qualitative health research. Qualitative Health Research, 16(2), 298-310.

Hurst, A. L. (2008). A healing echo: Methodological reflections of a working class researcher on class. Qualitative Report, 13(3), 334-352.

Kenny, A. (2016). Communities of musical practice. Abingdon: Routledge.

Kenny, A. (2018). Voice of Ireland? Children and music within asylum seeker accommodation. Research Studies in Music Education, 40(2), 211-225.

Malkki, L. (1997). News and culture: transitory phenomena and the fieldwork tradition. In J. Ferguson \& A. Gupta (Eds.), Anthropological locations: boundaries and grounds of a field science (pp. 86-101). Los Angeles: University of California Press.

Milner, R. H. (2007). Race, culture, and researcher positionality: Working through dangers seen, unseen and unforeseen. Educational Researcher, 36(7), 388-400.

Reynolds, T., \& Erel, U. (2016, January 22). Migrant mothers' creative interventions into citizenship. Open democracy. https://www.opendemocracy.net/en/migrant-mothers-creative-interven tions-into-citizenship/

Rich, A. (1995). Of woman born: Motherhood as institution and experience. New York: Norton.

Rose, J. (2018). Mothers: An essay on love and cruelty. London: Faber \& Faber Ltd..

Ruppel, P. S., Dege, M., Andrews, M., \& Squire, C. (2008). Tackling problems of qualitative social research: A conversation. Forum: Qualitative Social Research, 9(1), 41.

Srivastava, P. (2006). Reconciling multiple researcher positionalities and languages in international research. Research in Comparative and International Education, 1(3), 210-222.

Warren, C. A. B. (1988). Gender issues in field research. Newbury Park: Sage.

Weston, D., \& Lenette, C. (2016). Performing freedom: The role of musicmaking in creating a community in asylum seeker detention centres. International Journal of Community Music, 9(2), 121-134. 
Dr. Ailbhe Kenny is based at Mary Immaculate College, University of Limerick, Ireland. Ailbhe's research is widely published internationally; she is author of Communities of Musical Practice (2016) and coeditor of Musician-Teacher Collaborations: Altering the Chord (2018). She is a EURIAS fellow and Fulbright Scholar and holds a PhD from the University of Cambridge. Ailbhe is currently a PI on the HERA-funded project 'Night Spaces: Migration, Culture and Integration in Europe' (NITE). Ailbhe has held previous positions as a primary teacher, research fellow and as Arts and Education Officer at The Ark - a children's cultural centre. She is actively involved in community projects, including directing the MIC Children's Choir and working in asylum seeker centres.

Open Access This chapter is licensed under the terms of the Creative Commons Attribution 4.0 International License (http://creativecommons.org/licenses/by/4.0/), which permits use, sharing, adaptation, distribution and reproduction in any medium or format, as long as you give appropriate credit to the original author(s) and the source, provide a link to the Creative Commons license and indicate if changes were made.

The images or other third party material in this chapter are included in the chapter's Creative Commons license, unless indicated otherwise in a credit line to the material. If material is not included in the chapter's Creative Commons license and your intended use is not permitted by statutory regulation or exceeds the permitted use, you will need to obtain permission directly from the copyright holder.

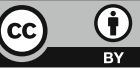

